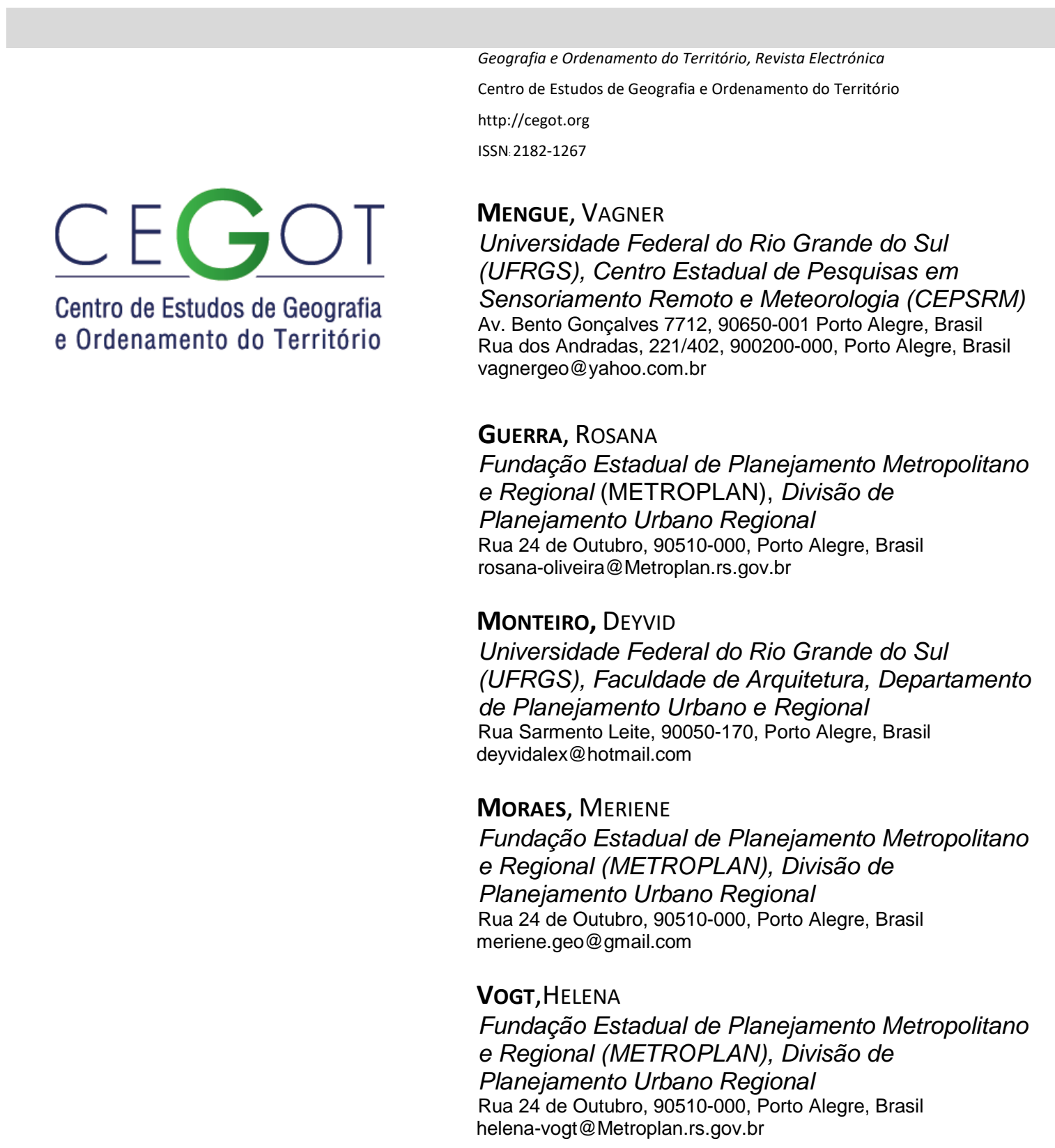

\title{
Análise da expansão urbana em áreas suscetíveis à inundação utilizando o modelo HAND: o caso da Região Metropolitana de Porto Alegre, Brasil
}

The Analysis of urban expansion in areas susceptible to flooding using the Model HAND: the case of the Porto Alegre Metropolitan Region, Brazil

Referência: Mengue, Vagner et. al (2017). Análise da expansão urbana em áreas suscetíveis à inundação utilizando o modelo HAND: o caso da Região Metropolitana de Porto Alegre, Brasil. Revista de Geografia e Ordenamento do Território (GOT), n. 12 (dezembro). Centro de Estudos de Geografia e Ordenamento do Território, p. 231-253, dx.doi.org/10.17127/got/2017.12.010 


\section{RESUMO}

O objetivo deste trabalho é contribuir para avançar no conhecimento acerca do potencial do Modelo HAND para avaliação e monitoramento da expansão urbana da Região Metropolitana de Porto Alegre (RMPA) em áreas suscetíveis à inundação. Como procedimento metodológico foi utilizada a combinação de imagens de iluminação noturna com índices de vegetação NDVI do satélite Landsat. Para identificar as áreas suscetíveis à inundação, foi utilizado o Modelo HAND. Foi identificado um aumento de 22,15\% da área urbana ocupada entre os anos 1985 e 2015. Com o Modelo HAND foi possível identificar que as novas ocupações urbanas estão situadas em cotas de até 2 metros de elevação em relação à drenagem mais próxima. Este dado evidencia que áreas identificadas como de expansão estão localizadas em cidades problemáticas do ponto de vista de inundações.

Palavras-chave: Expansão urbana, áreas suscetíveis, inundação, Modelo HAND, Região Metropolitana, Porto Alegre, Brasil.

\section{ABSTRACT}

The aim of this paper is to contribute to the progress in the knowledge about the HAND Model's potential for evaluation and monitoring of the urban expansion of the Porto Alegre's Metropolitan Region (RMPA), in areas susceptible to flooding. As a methodological procedure, the combination of nocturnal illumination images with NDVI vegetation indices of the Landsat satellite was used. The HAND Model was applied to identify areas susceptible to flooding. An increase of 22.15\% of the urban area occupied between 1985 and 2015 was identified. With the HAND Model it was possible to identify that the new urban occupations are located in quotas of up to 2 meters of elevation in relation to the nearest drainage. This data shows that the expansion areas identified are located in cities with floods problems.

Key words: Urban expansion, areas susceptible, flooding, HAND model, Metropolitan Region, Porto Alegre, Brazil

\section{Introdução}

A segunda metade do século XX marcou a aceleração do processo de urbanização no Brasil. Entre as diversas conseqüências deste processo, pode-se destacar: (i) a formação de regiões metropolitanas; (ii) a verticalização e o adensamento das áreas já urbanizadas; (iii) a expansão urbana para as áreas periféricas e (iv) a ocupação de áreas de risco, tais como áreas de várzea (inundação) e áreas com declive acentuado, como topos de morro (SANTOS, 2008; TUCCI, 2012).

Os processos de expansão urbana que se desenvolvem em escala metropolitana são diversos. De acordo com Alves \& Torres (2006), tais processos podem envolver tanto a dispersão espacial de grupos de baixa renda, marcados pela autoconstrução e por 
loteamentos irregulares e favelas, quanto de grupos de média e alta renda, exemplificados pelos condomínios fechados.

A dinâmica de ocupação irregular tem importantes impactos sociais e ambientais nas regiões metropolitanas. A expansão dessas áreas pode implicar na ausência de saneamento básico, principalmente na rede de esgoto e na poluição de rios e córregos. Além disto, a expansão urbana desordenada pode agravar situações de risco e de degradação ambiental, tais como enchentes e deslizamentos (TORRES et al., 2007). Na Região Metropolitana de Porto Alegre (RMPA), a grande maioria dos problemas relacionados ao meio físico é decorrente da ocupação de áreas inadequadas, como aquelas com declividade acentuada, ou cabeceiras de drenagem, fundos de vale, várzeas, vertentes altamente suscetíveis a movimentos de massa, entre outras (FUJIMOTO, 2002).

Um dos maiores problemas enfrentados com a expansão urbana desordenada na RMPA são as cheias dos seus principais rios. A problemática das inundações é histórica e acompanha a formação de diversos municípios. Ao longo das últimas décadas, as inundações têm provocado impactos negativos para a economia, com elevados prejuízos financeiros e problemas sociais, em especial, nas áreas urbanas localizadas nas planícies de inundação, como nos rios dos Sinos, Caí, Jacuí e Gravataí (BAZZAN et al., 2012).

O conhecimento do comportamento dos corpos hídricos em períodos de precipitação elevada é, portanto, de fundamental importância, porque pode evitar a perda de vidas humanas e prejuízos financeiros. Desse modo, técnicas de geoprocessamento e sensoriamento remoto têm oferecido importantes recursos para o mapeamento de recursos hídricos e o monitoramento das dinâmicas das águas de superfícies, em especial em áreas urbanas (Jl et al., 2009). Exemplo disso são trabalhos que utilizam técnicas de modelagem e análise espacial em conjunto com dados oriundos de sensoriamento remoto para o mapeamento de áreas de inundação, como o estudo de Opolot (2013) e os realizados na RMPA (SALDANHA et al., 1996; OLIVEIRA et al., 2011).

Existem diversos modelos para mapeamento de áreas suscetíveis à inundação. Uma nova abordagem, desenvolvida por pesquisadores do INPE (Instituto Nacional de Pesquisas Espaciais) e do INPA (Instituto Nacional de Pesquisas da Amazônia) é o modelo de terreno denominado HAND - Height Above Nearest Drainage (RENNÓ et al., 2008; NOBRE et al., 
2011). O modelo HAND tem sido usado no mapeamento da condição hidrológica estacionária do terreno e também no mapeamento de áreas suscetíveis à inundação. 0 modelo normaliza a topografia da paisagem, utilizando como dados de entrada Modelos Digitais de Elevação (MDT) e fornece como saída um novo MDT normalizado, que pode ser classificado de acordo com as distâncias verticais das drenagens mais próximas.

No Brasil existem trabalhos testando a aplicabilidade no modelo HAND em diversas regiões como no trabalho de Mengue et al (2016) que testaram o modelo HAND para mapeamento de áreas suscetíveis à inundação em áreas urbanas com o uso de dados SRTM, Momo et al (2016) que avaliaram o desempenho do modelo HAND no mapeamento de áreas suscetíveis à inundação, utilizando MDT de alta resolução espacial e o trabalho de Rennó et al (2008) nas planícies de inundação na Amazônia.

Desta forma, as áreas suscetíveis à inundação poderão ser monitoradas com maior periodicidade e menor custo devido à redução de deslocamentos ao campo, aumentando a eficácia e objetividade da fiscalização. Com isso, a fiscalização das leis, hoje dificultada pelo pequeno número de técnicos envolvidos no processo, custos associados aos deslocamentos ao campo e dificuldade de acesso a determinados aglomerados urbanos, poderia ser realizada em setores de planejamento das prefeituras por pequeno número de profissionais especializados na interpretação de dados de sensoriamento remoto (SR) e geoprocessamento.

Neste sentido, a presente pesquisa tem como objetivo contribuir para avançar no conhecimento acerca do potencial do Modelo HAND para avaliação e no monitoramento da expansão urbana da Região Metropolitana de Porto Alegre (RMPA) em áreas suscetíveis à inundação. Para isso, apresenta como hipótese que: a expansão da área urbana na Região Metropolitana de Porto Alegre está avançando sobre áreas não apropriadas, tais como áreas de inundação, e que tecnologias de SR e geoprocessamento, como séries temporais de imagem de satélite e modelos de elevação, podem fornecer subsídios para identificar tais características de ocupação. Cabe destacar que este trabalho faz parte de um projeto de pesquisa maior que está em desenvolvimento e visa contribuir para estudos acerca dos impactos da expansão urbana da RMPA. 


\section{Material e Métodos}

\section{1. Área de estudo}

A RMPA foi instituída em 1973 e está situada no Estado do Rio Grande do Sul. Composta, inicialmente, por 14 municípios, atualmente conta com 34 municípios (Figura 1), ocupando uma área total de $10.345,447 \mathrm{~km}^{2}$, na qual residem 4.282 .410 habitantes (IBGE, 2010).

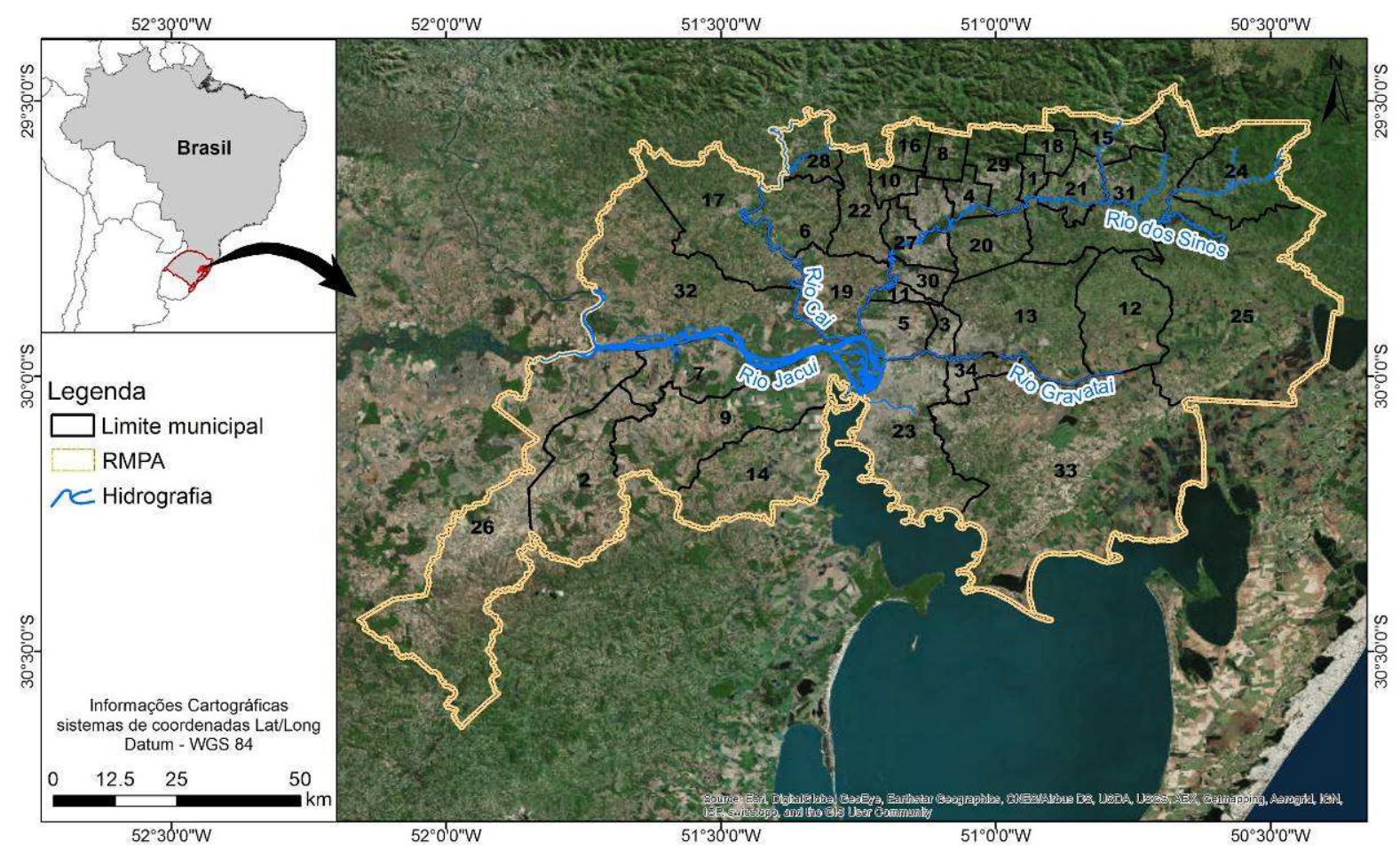

1. Araricá - 2. Arroio dos Ratos - 3. Cachoeirinha - 4. Campo Bom - 5. Canoas - 6. Capela de Santana - 7. Charqueadas - 8. Dois Irmãos - 9. Eldorado do Sul - 10. Estância Velha - 11. Esteio - 12. Glorinha - 13. Gravataí - 14. Guaíba - 15. Igrejinha 16. Ivoti - 17. Montenegro - 18. Nova Hartz - 19. Nova Santa Rita - 20. Novo Hamburgo - 21. Parobé - 22. Portão - 23. Porto Alegre - 24. Rolante - 25. Santo Antônio da Patrulha - 26. São Jerônimo - 27. São Leopoldo - 28. São Sebastião do Caí - 29. Sapiranga - 30. Sapucaia do Sul - 31. Taquara - 32. Triunfo - 33. Viamão - 34. Alvorada.

Figura 1 - Mapa de localização da Região Metropolitana de Porto Alegre (RMPA)

A região está localizada na porção centro-leste do Estado do Rio Grande do Sul/Brasil. Ao sul faz limite com a Lagoa dos Patos, ao norte localiza-se as áreas com maiores altitudes e com maior declive do terreno e ao Leste com uma distância de aproximadamente $50 \mathrm{~km}$ do litoral. A RMPA pertence, na sua maior parte, a Bacia Hidrográfica do Lago Guaíba e é cortada pelos Rios Caí, jacuí, Sinos e Gravataí e o encontro desses rios constituem um importante estuário, cuja preservação é fundamental tanto do ponto de vista biológico como hidrológico.

Com relação ao clima, conforme classificação de Köppen (1948), na RMPA predomina o tipo Cfa (subtropical chuvoso com verões quentes). No tocante às precipitações, a RMPA 
apresenta uma distribuição relativamente equilibrada das chuvas ao longo de todo o ano, com precipitação média entre 1.600mm e 1.800mm.

Para avaliação das áreas suscetíveis a inundação foi considerado o período de estudo foi de 1985 a 2015. O ano de 1985 foi escolhido como referência devido ao fato de que foi o período no qual a série temporal do Landsat-TM tem suas primeiras imagens livres de nuvens para a RMPA.

\subsection{Seleção, classificação das imagens, validação e geração do Modelo HAND}

Para quantificar as transformações ocorridas na área urbana ocupada da RMPA nos últimos trinta anos e identificar se houve avanços sobre áreas não apropriadas para ocupação, foram utilizadas imagens TM/Landsat 5 e OLI/Landsat 8 (órbita/ponto 221/81).

Para detecção da Área Urbana foi utilizada a metodologia proposta por LIN et al (2012), que utilizaram uma combinação de imagens de iluminação noturna com índices de vegetação NDVI. As imagens de iluminação noturna Defence Meteorological Satellite Program Operational Linescan System (DMSP-OLS), com resolução espacial de 550 metros, foram obtidas no endereço: https://ngdc.noaa.gov/eog/dmsp/downloadV4composites.html. Foram utilizadas as imagens do tipo stable lights, as quais são compostas por uma média anual de imagens colhidas pelo sensor. Dessa forma são eliminadas todas as fontes eventuais de iluminação, mantendo apenas as fontes de iluminação permanente, que são características de áreas urbanas.

O índice de vegetação NDVI foi calculado a partir das imagens de reflectância de superfície dos Satélites Landsat 5-TM e Landsat 8-OLI. As datas das imagens foram 06 de Fevereiro de 1985 e 24 de Janeiro de 2015, respectivamente. Para a detecção das áreas urbanas nas imagens Landsat foi definido um limiar $<0,50$ de NDVI, que forneceu os melhores resultados de acordo com testes empíricos usando -0,2 a 0,6 valores de NDVI, dado que valores baixos de NDVI representam áreas urbanas, corpos d'água, solo exposto e etc. Nas imagens noturnas DMSP-OLS para identificar as áreas urbanas, foi definido um limiar $>40$, definido através de testes empíricos, correspondendo às áreas com altas luminosidades. 
As imagens de NDVI e iluminação noturna foram reclassificadas de forma a separar em uma imagem booleana as áreas urbanas e não urbanas. A próxima etapa foi realizar uma operação overlay com as duas imagens booleanas, resultando em uma imagem que possui para as áreas urbanas apenas valores diferentes de zero. Após o processo de classificação, foi realizado um refinamento visual em tela para edição de possíveis erros classificatórios.

Para averiguação das exatidões espaciais (acurácia) das classificações das áreas urbanas, foram utilizados o índice de exatidão global $(E G)$, o índice de concordância Kappa (IK) (CONGALTON, 1991; CONGALTON \& GREEN, 1999); e as acurácias de usuário e produtor, tendo-se como referência terreste, as imagens de média resolução espacial (30 metros) Landsat de 1985 e 2015. Foram utilizadas cerca de 100 amostras (100 pontos), das quais metade foi obtida aleatoriamente, sobre o alvo de interesse (área urbana gerada pelas imagens Landsat e DMSP-OLS), e a outra metade foi sorteada aleatoriamente fora da área urbana. Desta maneira, procurou-se evitar que os erros de inclusão e omissão fossem mascarados na análise. Este processo foi realizado para os anos de 1985 e 2015.

Para identificar as áreas suscetíveis à inundação, foi utilizado o Modelo HAND, inserido no software livre TerraHidro. Este modelo possibilita a geração de simulações de cotas de inundações através de dados topográficos em formato matricial, resultando no mapeamento das áreas mais suscetíveis à inundação, fundamentando-se na distância vertical à drenagem mais próxima. No trabalho foram utilizados dados do Modelo Digital de Superfície (MDS) do SRTM (Shuttle Radar Topography Mission) como os dados de entrada.

Nobre et al (2011) e Rennó et al (2008) explicam que a partir da rede de drenagem extraída do dado topográfico, a diferença entre cada elemento da grade MDE e o ponto mais próximo associado à rede de drenagem extraída dá origem ao modelo de superfície HAND, portanto, o nível de referência deixa de ser fixo em relação ao mar e passa a ser relativo à rede de drenagem mais próxima. Abaixo, na Figura 2, é possível observar que o atributo de altitude de um determinado ponto é definido pela posição deste em relação ao curso d'água para o qual ele deságua, iniciando uma contagem a partir do zero e aumentando o valor na medida em que se distancia da drenagem. 


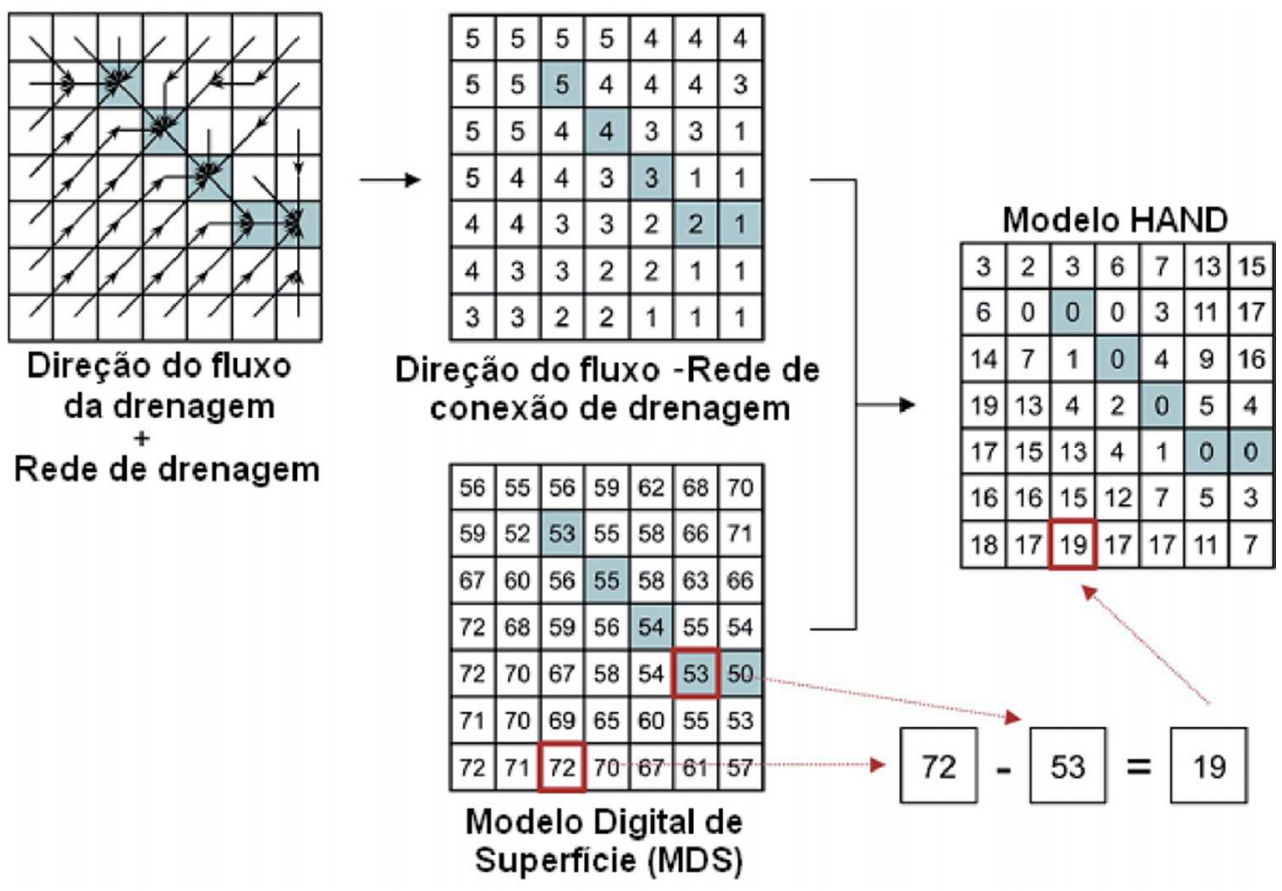

Figura 2 - Esquema de cálculo do modelo Hand: os quadrados marcados representam os pontos da grade que pertencem à rede de drenagem; somente as setas pretas são consideradas como direção de fluxo das drenagens (adaptado de Rennó et al., 2008).

A partir dos dados de elevação são calculadas as direções de fluxo e as áreas acumuladas de drenagem (Rodrigues et al., 2011). A resolução espacial dos dados SRTM é de 30 metros. A partir de diversos testes, foi definida a limiar de 500 (threshold) como parâmetro para geração da rede de drenagem, já que este representou melhor a hidrografia local da RMPA.

Para ajudar nas análises e interpretação dos resultados foi gerado um mapa de declividade com imagens de elevação SRTM. Foram considerados as classes de 0 a 3\%, 3 a 15\%, 15 a $30 \%$ e acima de $30 \%$ como sendo intervalos de declividade para o estudo de fragilidade natural à ocupação urbana. As classes de declividade foram definidas por Instituto de Pesquisas Tecnológicas - IPT (1991), o atual Código Florestal Brasileiro (Lei atual : Lei 12.651/12) e a a Lei Federal no 6.766/79 de parcelamento do Solo.

\subsection{Quantificação e análise da expansão urbana na RMPA}

A quantificação e análise dos processos de transformação da área urbana nos últimos trinta anos foi efetuada com base em uma tabulação cruzada entre o mapa de área urbana de 1985 e 2015. A partir deste procedimento foi possível quantificar e mapear as áreas que 
apresentaram ganhos ou perdas e identificar se existe avanço sobre áreas susceptíveis à inundação e áreas com declividades acentuadas, que são áreas onde a ocupação urbana deve ser evitada. Através de gráficos e tabelas gerados pelo módulo Land Change Modeler IDRISI Taiga (LCM) foi possível analisar e quantificar as transformações espaciais ocorridas nos últimos 30 anos na área de estudo.

A etapa seguinte foi quantificar espacialmente e temporalmente as mudanças nos últimos trinta anos para a RMPA. As áreas onde existe a mudança para área urbana, foram cruzadas com o mapa HAND de inundação e com o mapa de declividade e analisado o resultado por município.

Para analisar os processos da expansão urbana na RMPA, foram utilizados os limites dos setores censitários do ano 2010, do Instituto Brasileiro de Geografia e Estatística (IBGE). Setor Censitário é a unidade territorial de coleta das operações censitárias, definidas pelo IBGE, com limites físicos identificados, em áreas contínuas e respeitando a divisão políticoadministrativa da RMPA. A RMPA foi dividida em 7.231 setores censitários, dos quais 6.815 estão classificados como área urbana e 506 como área rural. A utilização dos setores censitários para análise é importante, pois permite identificar em quais regiões está acontecendo o processo de expansão urbana.

\section{Resultados e discussão}

\subsection{Análise da expansão da área urbana ocupada}

Através da classificação das áreas urbanas com as imagens Landsat para os anos de 1985 e 2015 foi possível identificar as áreas de expansão da mancha urbana para toda a RMPA. Na Figura 3, abaixo, é possível analisar as manchas urbanas de 1985 e 2015 classificadas com as imagens Landsat. 


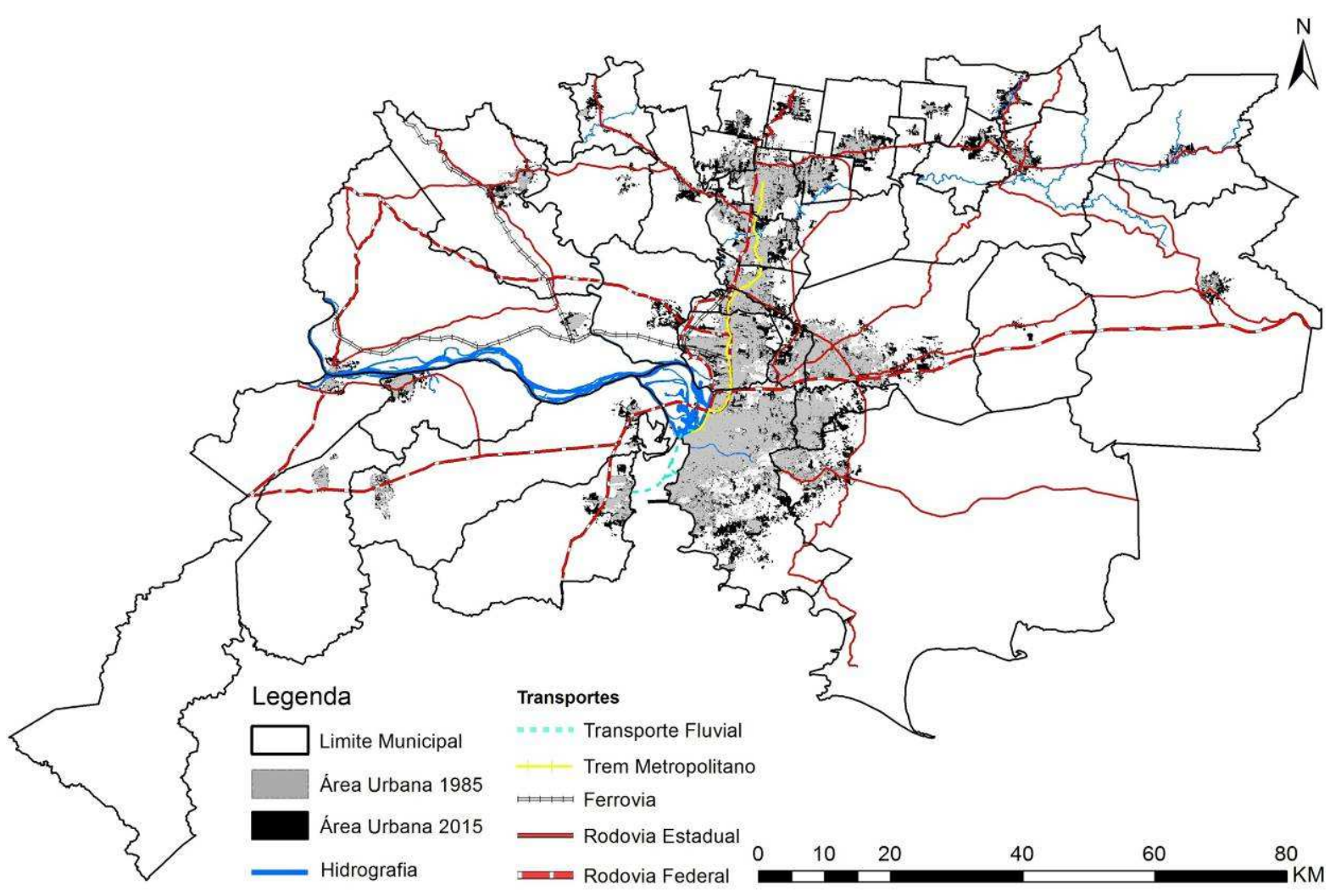

Figura 3 - Classificação da área urbana para os anos de 1985 e 2015 para a RMPA.

As classificações das áreas urbanas para os anos de 1985 e 2015, apresentaram exatidão global de 92,0 \% e 94,0\%, respectivamente (Tabela 01). Já o índice kappa, apresentou valores de 0,84 para o ano de 1985 e 0,88 para o ano de 2015. Trabalhos que utilizaram metodologia similar, mas com outro sensor para extração do índice de vegetação (NDVI), tiveram resultados positivos, como no trabalho de Cao et al (2009) que utilizaram imagens DMSP-OLS e dados SPOT/Vegetation, encontrando valores entre $71,7 \%$ e $98,8 \%$ de exatidão global. No trabalho de Lin et al (2014) encontraram valores superiores a 75\% de acurácia, classificando áreas urbanas na China, com o uso combinado de NDVI e imagens reflectância do MODIS e dados DMSP-OLS, a conclusão foi que o resultado da classificação é muito similar ao classificado com Landsat e muito melhor do que o produto MODIS (MCD12Q1) de cobertura terrestre.

Importante mencionar que a combinação das imagens noturnas (DMSP-OLS) conseguiu eliminar a chance de classificar erroneamente outros usos do solo com similaridade espectral, como solo exposto, água, etc. O ideal é que os erros de classificação sejam os menores possíveis, mas cabe ressaltar que o levantamento é em nível regional e realizado 
de forma rápida, sistemática, com baixo custo e podendo a metodologia ser aplicada em outras regições metropolitanas brasileiras.

\begin{tabular}{|c|c|c|c|c|}
\hline \multicolumn{5}{|c|}{1985} \\
\hline \multirow{2}{*}{ Classificação } & \multicolumn{2}{|c|}{ Referência de campo } & \multirow{2}{*}{ Total } & \multirow{2}{*}{$\begin{array}{l}\text { Acurácia do } \\
\text { usuário (\%) }\end{array}$} \\
\hline & Área Urbana & Não Urbana & & \\
\hline Área Urbana & 43 & 1 & 44 & 97,7 \\
\hline Não Urbana & 7 & 49 & 56 & 87,5 \\
\hline Total & 50 & 50 & 100 & \\
\hline Acurácia do produtor (\%) & 86,0 & 98,0 & & \\
\hline \multicolumn{5}{|c|}{2015} \\
\hline \multirow{2}{*}{ Classificação } & \multicolumn{2}{|c|}{ Referência de campo } & \multirow{2}{*}{ Total } & Acurácia do \\
\hline & Área Urbana & Não Urbana & & usuário (\%) \\
\hline Área Urbana & 46 & 2 & 48 & 95,8 \\
\hline Não Urbana & 4 & 48 & 52 & 92,3 \\
\hline Total & 50 & 50 & 100 & \\
\hline Acurácia do produtor (\%) & 92,0 & 96,0 & & \\
\hline
\end{tabular}

Tabela 01: Matriz de confusão da classificação da área urbana para os anos de 1985 e 2015

Para o cálculo da expansão urbana, foram consideradas apenas as áreas dos setores censitários classificados como urbanos. A taxa média de crescimento para a RMPA foi de 22,15\% nos últimos 30 anos (Tabela 2) conforme dados obtidos com a classificação Landsat, a área total foi de $24.590,34$ ha. 


\begin{tabular}{|c|c|c|c|c|c|c|}
\hline Municípios & & $\begin{array}{c}\text { Evolução para Área } \\
\text { Urbana* (\%) }\end{array}$ & $\begin{array}{l}\text { Área Total } \\
\text { (ha) }\end{array}$ & $\begin{array}{l}\mathrm{N}^{\circ} \text { setores } \\
\text { censitários }\end{array}$ & Declividade (\%) & HAND (m) \\
\hline ALVORADA & & 16.26 & 827.87 & 273 & 5.34 & 10.42 \\
\hline ARARICÁ & & 13.30 & 66.24 & 23 & 6.32 & 9.04 \\
\hline ARROIO DOS RATOS & & 13.63 & 106.51 & 27 & 5.62 & 12.47 \\
\hline CACHOEIRINHA & & 19.32 & 938.46 & 206 & 4.65 & 7.50 \\
\hline CAMPO BOM & & 25.77 & 644.73 & 81 & 8.78 & 20.07 \\
\hline CANOAS & & 24.80 & 2156.62 & 601 & 4.15 & 5.39 \\
\hline CAPELA DE SANTANA & & 18.13 & 72.20 & 15 & 7.12 & 19.27 \\
\hline CHARQUEADAS & & 14.02 & 275.49 & 49 & 4.94 & 6.74 \\
\hline DOIS IRMÃOS & & 29.70 & 428.07 & 44 & 10.04 & 26.66 \\
\hline ELDORADO DO SUL & & 25.38 & 526.65 & 60 & 4.45 & 7.03 \\
\hline ESTÂNCIA VELHA & & 29.11 & 630.13 & 82 & 9.35 & 22.68 \\
\hline ESTEIO & & 21.53 & 399.98 & 150 & 4.36 & 5.60 \\
\hline GLORINHA & & 25.00 & 85.40 & 4 & 4.41 & 8.20 \\
\hline GRAVATAÍ & & 18.41 & 1650.78 & 412 & 5.27 & 10.42 \\
\hline GUAÍBA & & 24.57 & 820.13 & 129 & 5.72 & 9.14 \\
\hline IGREJINHA & & 20.34 & 459.95 & 74 & 7.54 & 10.72 \\
\hline IVOTI & & 30.52 & 315.11 & 29 & 8.78 & 50.45 \\
\hline MONTENEGRO & & 23.16 & 489.50 & 114 & 6.89 & 13.59 \\
\hline NOVA HARTZ & & 17.21 & 160.88 & 34 & 5.38 & 8.92 \\
\hline NOVA SANTA RITA & & 15.72 & 394.23 & 39 & 6.82 & 12.75 \\
\hline NOVO HAMBURGO & & 31.49 & 1576.60 & 449 & 8.25 & 14.93 \\
\hline PAROBÉ & & 39.95 & 646.07 & 78 & 7.46 & 12.80 \\
\hline PORTÃO & & 35.35 & 455.68 & 46 & 5.96 & 9.72 \\
\hline PORTO ALEGRE** & & 14.30 & 4358.41 & 2433 & 7.01 & 15.04 \\
\hline ROLANTE & & 13.39 & 146.90 & 33 & 7.57 & 9.49 \\
\hline $\begin{array}{l}\text { SANTO ANTÔNIO } \\
\text { PATRULHA }\end{array}$ & DA & 15.09 & 359.10 & 79 & 5.55 & 10.31 \\
\hline SÃO JERÔNIMO & & 9.15 & 137.97 & 34 & 5.18 & 7.58 \\
\hline SÃO LEOPOLDO & & 26.64 & 1552.51 & 376 & 5.86 & 10.81 \\
\hline SÃO SEBASTIÃO DO CAÍ & & 15.28 & 248.97 & 36 & 7.26 & 10.99 \\
\hline SAPIRANGA & & 40.24 & 886.51 & 127 & 6.22 & 11.00 \\
\hline SAPUCAIA DO SUL & & 24.49 & 772.17 & 256 & 6.00 & 12.93 \\
\hline TAQUARA & & 30.75 & 525.50 & 102 & 6.83 & 12.27 \\
\hline TRIUNFO & & 8.11 & 247.12 & 27 & 6.38 & 8.94 \\
\hline VIAMÃO & & 22.92 & 1227.89 & 293 & 8.45 & 21.48 \\
\hline Total & & 22.15 & 24590.34 & 6815 & 6.47 & 13.10 \\
\hline
\end{tabular}

Tabela 2: Quantificação das mudanças para área urbana para todos os municípios da RMPA e as estatísticas de declividade (\%) média e Altura em relação à drenagem mais próxima (HAND). *Média somente nos setores censitários urbanos. ${ }^{* *}$ Capital da RMPA. 
Conforme observado na Tabela 2, os municípios localizados ao norte da RMPA possuem as maiores taxas de crescimento da mancha urbana. Municípios como Sapiranga e Parobé tiveram crescimento de $40,24 \%$ e $39,95 \%$, respectivamente, bem acima da média da RMPA. Importante mencionar que no período de 1955 a 1965 o crescimento no eixo leste da RMPA foi superior ao do eixo norte. O preço médio dos terrenos era mais baixo nessa região, principalmente nas áreas de inundação ao Rio dos Sinos.

Uma das explicações sobre as maiores taxas de expansão dos municípios localizados ao norte da RMPA, tem relação direta com a construção de novas rodovias a partir da década de 70. Com as novas rodovias e melhoria dos principais eixos viários existentes, como a BR290, ligando Porto Alegre diretamente ao litoral; a RS-239, interligando os municípios de Estância Velha, Novo Hamburgo, Campo Bom, Sapiranga, Nova Hartz e Parobé; bem como a BR-386, possibilitando a conexão da RMPA com o noroeste do Estado, intensificaram-se as relações intra-regionais e os fluxos entre a RMPA e o restante do país. Outro fator relevante é o preço médio das terras na região norte da RMPA ser mais baixo em relação aos municípios mais próximos a Porto Alegre.

A expansão da área urbana ocupada nos eixos leste-oeste tende a ocorrer com mais intensidade no setor leste ao longo das rodovias RS-030 e BR-290 (Freeway), embora segregada, esta última rodovia, com poucas possibilidades de acesso, é um elemento indutor forte. Na classificação com as imagens Landsat foi possível identificar o processo de expansão da mancha urbana neste setor. Os distritos industriais dos municípios de Gravataí e Cachoeirinha, criados na década de 1970, ampliaram consideravelmente o processo de industrialização no eixo leste-oeste da RMPA, junto à BR-290. As indústrias de Porto Alegre foram transferidas para as cidades limítrofes, a partir das políticas de desenvolvimento urbano. Neste processo, uma das cidades que mais recebeu novas indústrias foi Gravataí, especialmente com a instalação da fábrica da General Motors (GM), no Complexo Industrial Automotivo de Gravataí (CIAG), em 1997 (SCHEREN, 2014).

Outro fator importante que poderá ser um indutor da expansão da área urbana ocupada é com a conclusão da nova ponte e duplicação da BR-116, ligando Porto Alegre a Eldorado do Sul, em direção a Pelotas e ao porto de Rio Grande, fortalecendo a tendência de se ocupar novas áreas no município de Eldorado do Sul. Este município é bastante problemático do 
ponto de vista de inundações na área urbana, pois está localizado em áreas baixas, com cotas não superiores a 2 metros em relação à drenagem mais próxima, conforme dados encontrados com o modelo HAND (Figura 4).

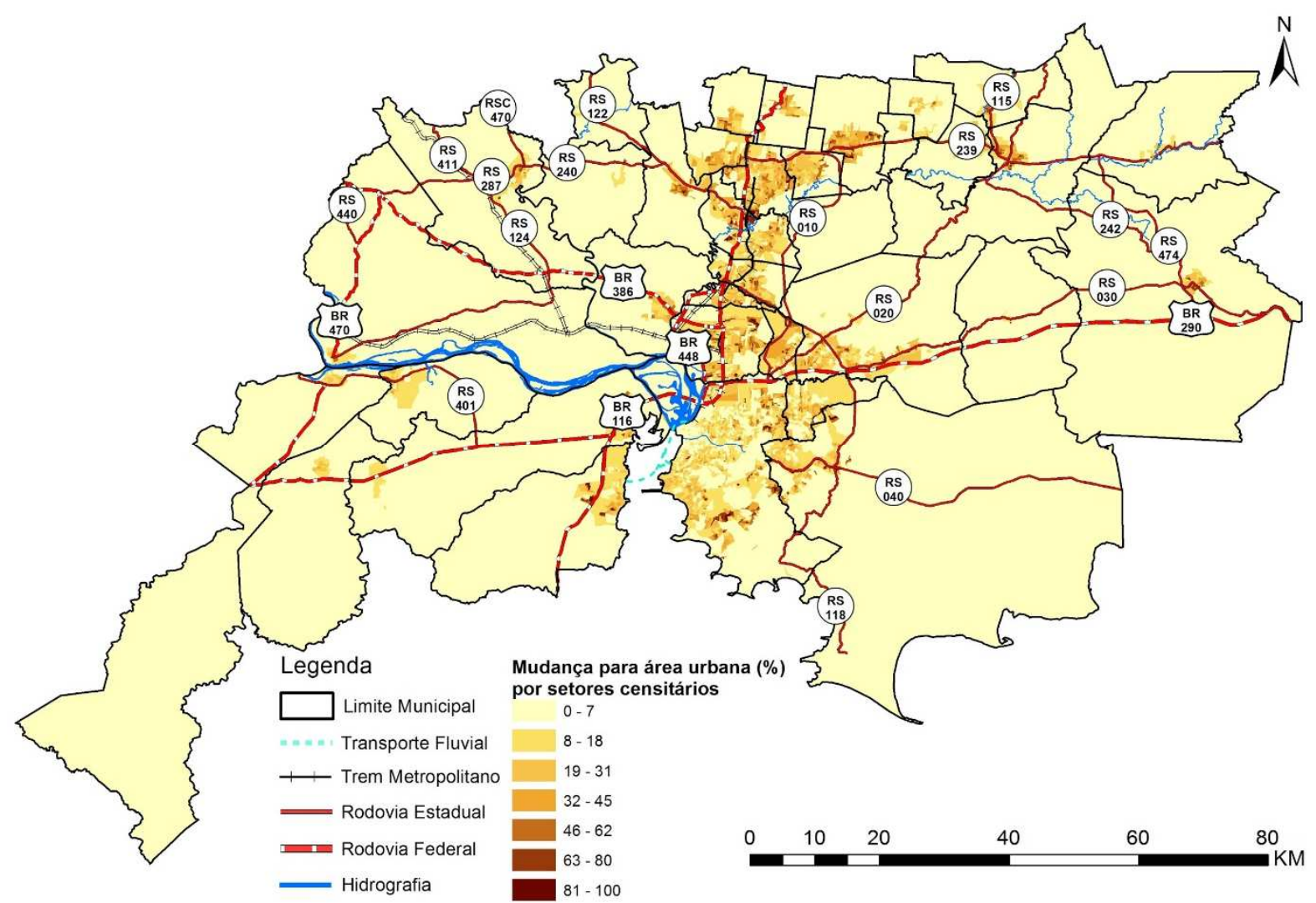

Figura 4 - Mudança para área urbana (\%) no período de 30 anos por setores censitários para toda a RMPA.

\section{1. Áreas suscetíveis à inundação com o Modelo HAND}

Com relação às áreas suscetíveis à inundação geradas pelo Modelo HAND, foi possível identificar sobre quais áreas a expansão urbana está avançando. Na Tabela 2 foi possível visualizar a quantificação por município e a média para toda a RMPA do Modelo HAND sobre as áreas com expansão urbana, os municípios localizados ao norte da área de estudo, possuem as maiores alturas em relação à drenagem mais próxima (HAND), o que faz sentido, já que nessa região é onde existem as ocupações urbanas com as maiores declividades e áreas de maiores altitudes. Já as áreas localizadas nas planícies de inundação dos rios do Sinos, Gravataí e Jacuí, possuem os menores valores HAND e as menores declividades, na Figura 5 é possível visualizar a expansão urbana entre 1985 e 2015 e as áreas classificadas com o Modelo HAND. 


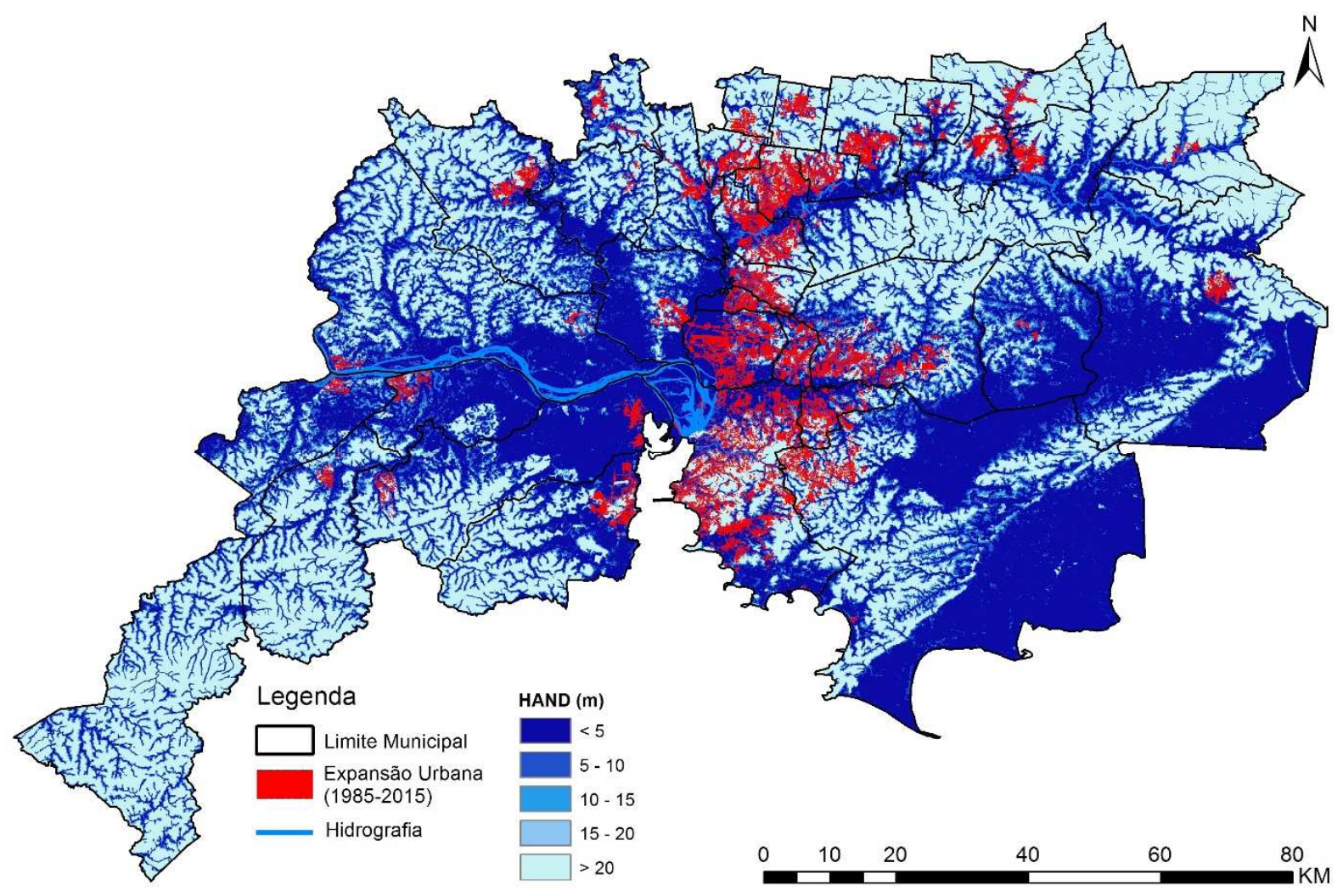

Figura 5 - Áreas suscetíveis à inundação geradas com o modelo HAND e a classificação da expansão urbana entre 1985 e 2015.

Através dos dados HAND foi possível identificar que mais de $80 \%$ de toda expansão urbana nos últimos 30 anos na RMPA está concentrada em alturas de até 20 metros em relação à drenagem mais próxima (Figura 6-A). Este resultado é preocupante, porque estas áreas são suscetíveis a inundações periódicas causando enormes prejuízos econômicos e de saúde pública para a população que habita nestas áreas. Cabe mencionar que mais de $99,6 \%$ da área de expansão urbana da RMPA no período estudado está situada em terrenos com declividades inferiores a 30\% (Figura 6-B), que conforme a Lei Federal no 6.766/79 de parcelamento do Solo é o limite máximo para novos projetos de parcelamento urbano. Portanto, é possível inferir por meio desses resultados que a expansão urbana da RMPA está concentrada em terrenos baixos e com baixas declividades, reforçando a ideia de que o poder público tem que aumentar o controle e planejamento sobre a expansão urbana ocupada em áreas de inundação. 

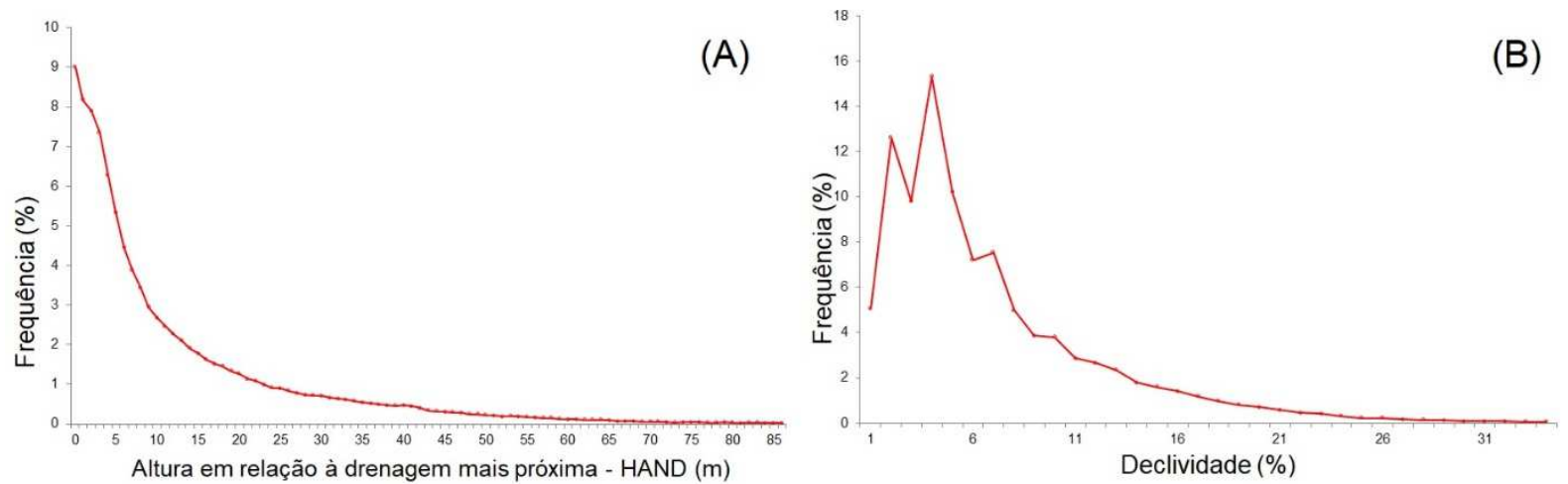

Figura 6 - Frequência para as áreas com expansão urbana em 30 anos para o Modelo HAND (A) e para declividade (B).

Em torno de $25 \%$ das novas ocupações urbanas estão situadas em cotas de até 2 metros de elevação em relação à drenagem, o que representa 6.730,47 hectares. Portanto, é uma área considerável do ponto de vista territorial e com grandes chances de enchentes periódicas, devido a pouca elevação da cota em relação à drenagem mais próxima.

Outro fator importante para a ocupação e expansão urbana nas áreas de inundação foram as obras de combate às cheias, como a construção de diques, destinados ao isolamento de áreas ribeirinhas com cotas topográficas inferiores aos níveis do curso d'água em situações de enchentes (CANHOLI, 2014). Os diques de proteção modificaram as direções de expansão das cidades pelo saneamento de áreas, muitas das quais deixaram de ter uso agrícola para serem loteadas. Sendo assim, é possível inferir que a falta de um planejamento geral para a RMPA permitiu que zonas inadequadas fossem ocupadas.

A ocupação em áreas suscetíveis a inundações também se deve à precariedade de informações obtidas nos setores públicos. Até 15 de agosto de 1990, o Departamento Nacional de Obras e Saneamento (DNOS) não havia transferido suas atribuições e acervo técnico-patrimonial para diferentes órgãos, a decreto de sua extinção (DECRETO no 99.240, de 7 de Maio de 1990). Esse órgão era responsável por estudos hidrológicos das bacias, o qual restringia áreas para a ocupação de solo. Assim, devido à extinção do órgão que fornecia dados confiáveis para o parcelamento do solo na época, não existem estudos atualizados nem finalizados para tal análise.

Cabe ressaltar que o incentivo de novas ocupações urbanas pelo poder público em áreas de inundação deve ser evitado, conforme aponta Tucci (2012), o planejamento urbano deve 
procurar mitigar este impacto através de ações preventivas para estes espaços. A população de maior poder aquisitivo tende a habitar os locais seguros ao contrário da população carente que ocupa as áreas de alto risco de inundação, provocando problemas sociais que se repetem por ocasião de cada cheia na região. Quando a frequência das inundações é baixa, a população tende a ganhar confiança e despreza os riscos, aumentando significativamente o investimento e a densificação das áreas inundáveis. Nessa situação, a enchente pode assumir características catastróficas.

Existem inúmeros problemas na RMPA referentes a inundações em áreas onde existem obras de contenção de cheias, mas por descaso do poder público, como a manutenção ineficiente das casas de bombas e problemas estruturais dos diques, essas áreas são frequentemente afetadas por inundações. Na Figura 7 é possível visualizar a planície de inundação do Rio dos Sinos durante um período de cheia e a área urbana do município de Esteio.

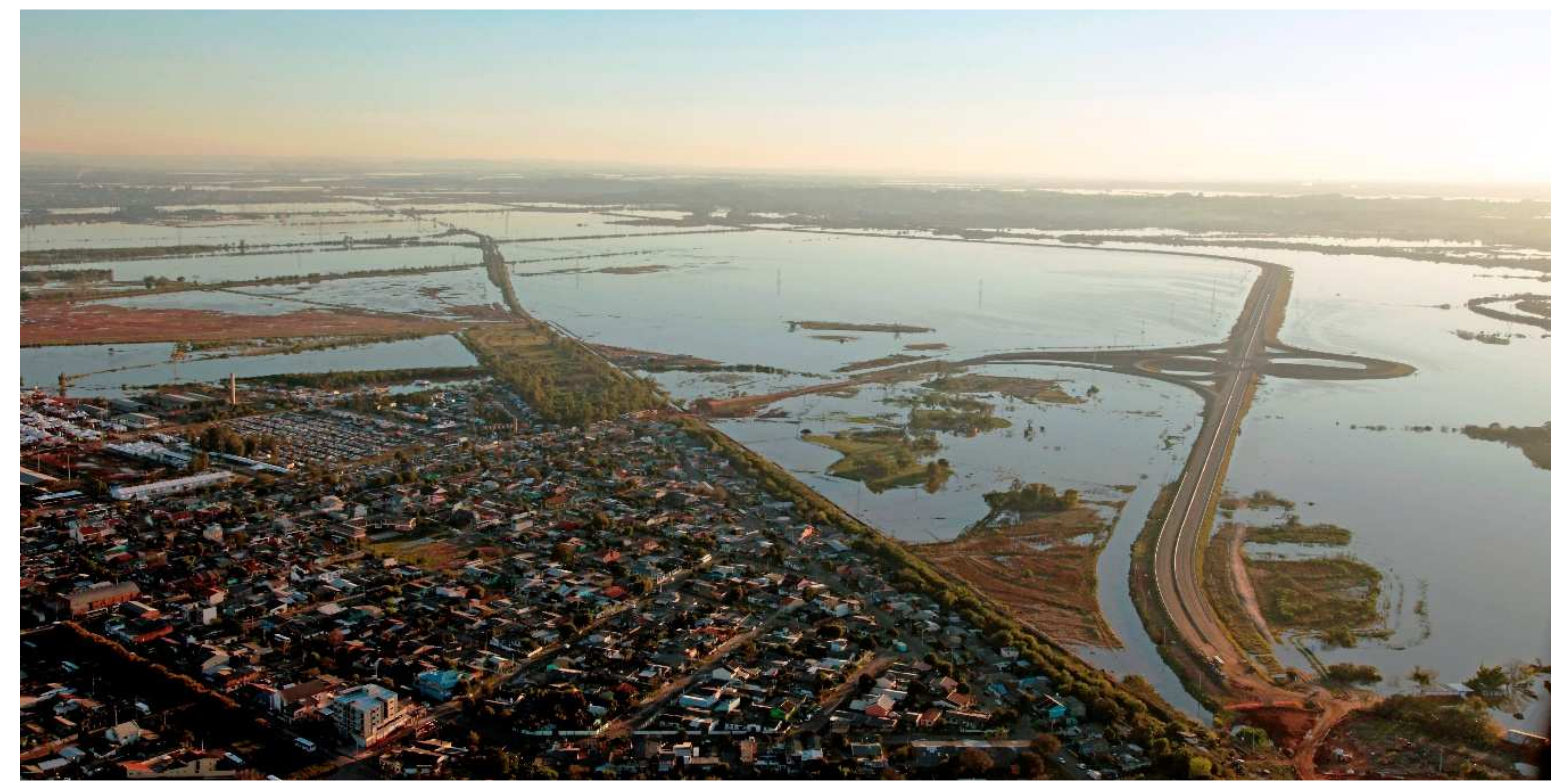

Figura 7 - Fotografia aérea da enchente de agosto de 2013, área urbana do município de Esteio. Ao fundo, a planície de inundação do Rio dos Sinos.

Fonte: Acervo METROPLAN, 2017

Com relação aos dados da simulação das áreas suscetíveis à inundação do modelo HAND, a eficiência deste é estreitamente relacionada com a qualidade (resolução espacial) do dado topográfico. Importante destacar que os dados SRTM possuem algumas características indesejáveis do ponto de vista da modelagem topográfica (Valeriano \& Abdon, 2007). Esses dados são sensíveis a quaisquer objetos presentes na superfície do terreno, tais como 
antenas, edificações e mesmo a cobertura vegetal, dificultando a percepção somente da superfície do terreno. Portanto, simulações de inundações com o modelo HAND realizadas com dados SRTM não representam a superfície do terreno, aumentando os valores reais, pois incluem também as altitudes de topo de construções urbanas e formações vegetais arbóreas, principalmente as de grande porte.

Na Figura 8-C é possível verificar esse processo, na simulação de cota de cheia acima de 4 metros com o modelo HAND (áreas claras) os dados SRTM registraram a altura dos prédios com maior elevação (Figura 8-A) e da mesma forma a mata ciliar do Arroio Sapucaia. Cabe salientar que isso acabou influenciando a qualidade do modelo HAND em prever áreas suscetíveis à inundação. Em razão disso, a simulação realizada para a RMPA apresenta falhas devido a superfície do terreno não ser corretamente representada.
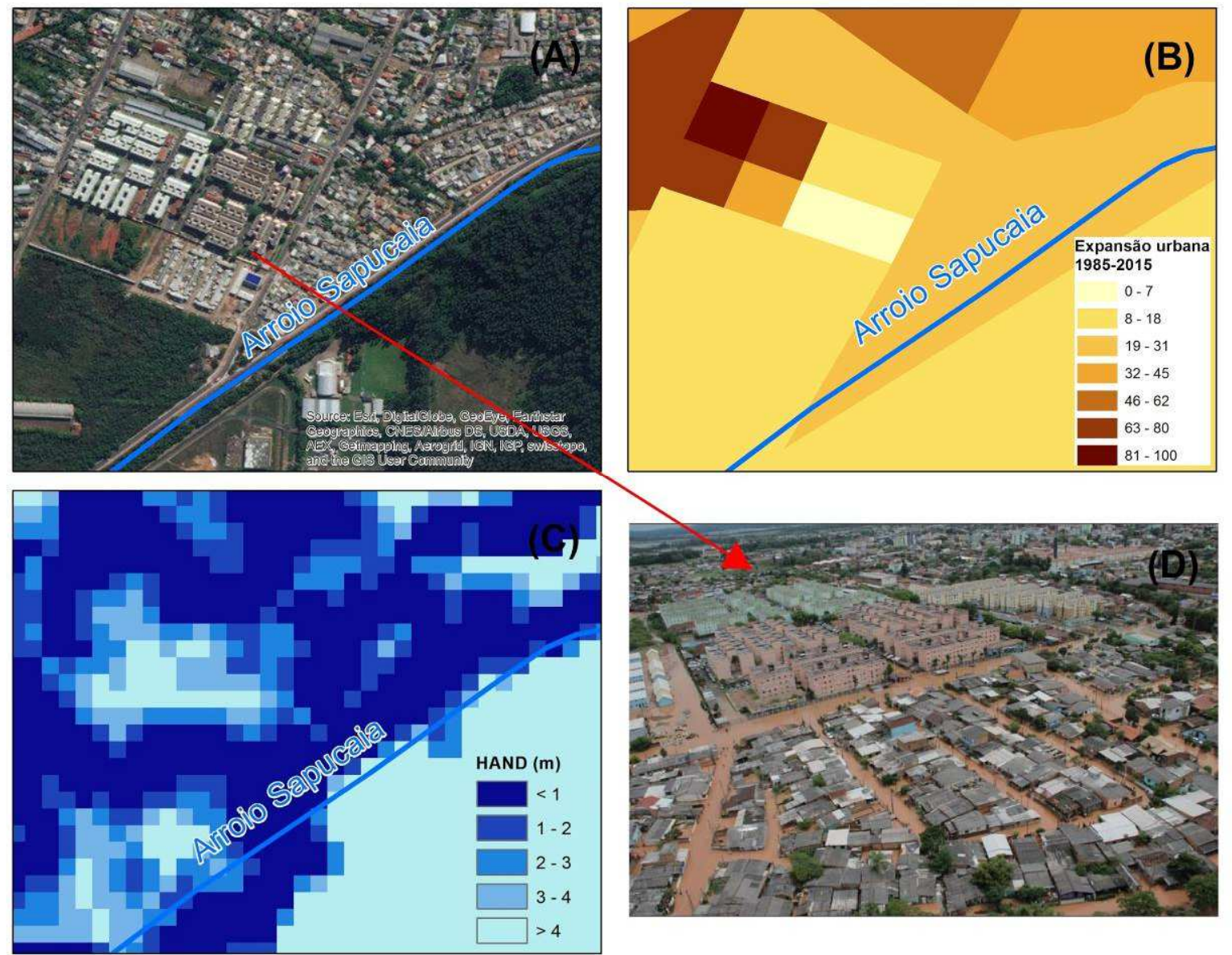

Figura 8: Área de ocupação urbana próxima ao Arroio Sapucaia (A) onde foi registrado aumento da mancha urbana (B), no modelo HAND é possível visualizar que está região está situada em áreas com elevação muito baixa (C) e a imagem aérea da cheia em Outubro de 2013 (D). 
Esse tipo de problema já era esperado quando se optou por trabalhar com os dados SRTM, mas como possuem a grande vantagem de serem gratuitos, de fácil manipulação e grande cobertura territorial, no intuito de um trabalho investigativo e de testes de simulação como foi este trabalho, é perfeitamente justificável a escolha desses dados. O ideal é que sempre se use Modelos Digitais do Terreno (MDT), que eliminam topo de prédios, vegetação arbórea densa, ao invés do Modelo Digital de Superfície (MDS). Cook \& Merwade (2009) utilizaram dados LIDAR (Light Detection And Ranging) para dois modelos de simulação (HECHAS 1D e modelo FESWMS 2D). A utilização de dados de entrada LIDAR para o Modelo HAND parece ser uma ótima opção para trabalhos futuros, já que carece de estudos para testar o potencial para simulações de áreas suscetíveis à inundação, principalmente em áreas urbanas situadas em planícies de inundação, com é o caso da RMPA.

No estudo de Momo et al (2016) foi realizada uma avaliação do desempenho do modelo HAND no mapeamento de áreas suscetíveis à inundação em dois municípios (Blumenau e Brusque) no Estado de Santa Catarina com imagens de alta resolução espacial, oriundas de um levantamento aerofotogramétrico com resolução espacial de 0,39 $\mathrm{m}$. Concluíram que o modelo HAND tem grande potencial de acerto para identificar áreas de inundação, principalmente com dados de alta resolução espacial e que o desempenho foi menor para as cotas de inundação mais baixas, onde as variações hidrodinâmicas são mais expressivas, melhorando para as cotas de inundação mais elevadas. Isto permite considerar que em regiões com reduzidas variações hidrodinâmicas, como em trechos inferiores de cursos de águas, o desempenho do modelo HAND tende a ser mais elevado.

\section{Considerações finais}

A hipótese de que as ocupações urbanas estão avançando sobre áreas não apropriadas, como áreas de inundação, foi confirmada através do uso das imagens de satélite Landsat e o modelo HAND.

A combinação das imagens de iluminação noturna (DMSP-OLS) com as imagens TM/Landsat-5 e OLI/Landsat-8 permitiu identificar e quantificar o aumento de 
aproximadamente $24.590,34$ hectares da área urbana ocupada entre os anos 1985 e 2015 na RMPA, o que corresponde a um incremento na ordem de $22,15 \%$.

Com a geração do modelo HAND foi possível normalizar as cotas em relação à drenagem mais próxima e cruzar com a classificação da expansão urbana ocupada da RMPA. Neste caso, mais de $80 \%$ de toda a expansão urbana está concentrada em áreas com cotas de até 20 metros. Com a elaboração do mapa de declividade foi possível afirmar que a expansão urbana não está concentrada em altas declividades, mas sim em áreas com terrenos baixos.

Cotas mais baixas identificadas com o modelo HAND menor que 2 metros, correspondem a $25 \%$ das novas ocupações urbanas, o que representa $6.730,47$ hectares. Este dado evidencia um resultado preocupante, pois muitas áreas identificadas como expansão estão localizadas em cidades problemáticas do ponto de vista de inundações, como Eldorado do Sul, Sapucaia do Sul e Guaíba, pois a sua área urbana está localizada em cotas baixas em planície de inundação dos rios que compõem a RMPA.

Recomenda-se a utilização de Modelos Digitais do Terreno com melhor resolução espacial, ao invés de Modelos Digitais de Superfície, como o SRTM, uma vez que estes dados comprometem a qualidade da geração do Modelo HAND para identificação de áreas de inundação.

Como recomendação para trabalhos futuros é a utilização de dados de entrada para o modelo HAND com imagens de alta resolução através de levantamento aerofotogramétrico oriundos do Plano de Prevenção e Combate às Cheias, já que o Estado do Rio Grande do Sul foi contemplado com R\$2 258 milhões do Plano Nacional de Gestão de Riscos e Respostas a Desastres Naturais (Programa de Aceleração do Crescimento - PAC 2) do Ministério das Cidades do Governo Federal. Assim que os dados do levantamento aerofotogramétrico estiverem disponíveis será possível ampliar e melhorar a qualidade de detecção das áreas suscetíveis à inundação com o modelo HAND.

Em adição, sugere-se que trabalhos futuros relacionem a expansão urbana com outras variáveis, como, por exemplo, a densidade populacional e ainda a integração dos dados dos setores censitários com dados socioeconômicos para identificar as características da população das áreas de expansão. 
Por fim, os resultados apresentados neste estudo contribuem para o mapeamento de áreas suscetíveis à inundação na RMPA, podendo servir como base para implantação de políticas públicas de planejamento e gestão da região metropolitana.

\section{Agradecimentos}

Os autores agradecem os Arquitetos Urbanistas Cláudio Ugalde e Gilda Jobim e à Socióloga Jussara Pires, pelas valiosas contribuições para o desenvolvimento desta pesquisa.

\section{Referências}

ALVES, H. P. F.; TORRES, H. G. Vulnerabilidade Socioambiental na Cidade de São Paulo: uma análise de famílias e domicílios em situação de pobreza e risco ambiental. Revista São Paulo em Perspectiva [online]. Vol. 20. № 1. Jan.-Mar. 2006, p. 44-60. Disponível em http://produtos.seade.gov.br/ produtos/spp/v20n01/v20n01 04.pdf, acesso em Jul.2017. ISSN 1806-9452.

BAZZAN, T.; ROBAINA, L. E. S. ; RECKZIEGEL, E. W. . Mapeamento das Áreas com Suscetibilidade e Perigo de Inundação do Rio dos Sinos, RS. In: Congresso Brasileiro Sobre Desastres Naturais, 2012, Rio Claro/SP. Anais do Congresso Brasileiro Sobre Desastres Naturais, 2012. p. 1-11.

CAO, X.; CHEN, J.; IMURA, H.; HIGASHI, O. A SVM-based method to extract urban areas from DMSP-OLS and SPOT VGT data. Remote Sensing of Environment. V.113, 2205-2209, 2009.

CANHOLI, A. P. Drenagem urbana e controle de enchentes. 2ạ ed. São Paulo: Oficina de Textos, 2014. ISBN 97885-7975-160-8.

CONGALTON, R.G. A review of assessing the accuracy of classifications of remotely sensed data. Remote Sensing of Environment, v.37, p.35-46, 1991.

CONGALTON, R.G.; GREEN, K. Assessing the accuracy of remotely sensed data: principles and practices. Boca Raton: CRC Press, 1999. 160p.

COOK, A.; MERWADE, V. Effect of topographic data, geometric configuration and modeling approach on flood inundation mapping. Journal of Hydrology, v.377, n.1, p.131-142, 2009. doi:10.1016/j.jhydrol.2009.08.015.

CUNHA, M. A. (Coord.). Manual de Ocupação de Encostas. São Paulo: Instituto de Pesquisas Tecnológicas (IPT), 1991. 223p.

FUJIMOTO, N. S. M. Implicações ambientais na área metropolitana de Porto Alegre-RS: Um estudo geográfico com ênfase na geomorfologia urbana. GEOUSP: Espaço e Tempo [online]. № 12. Dez. 2002, p. 141-177. Disponível em: <http://www.revistas.usp.br/geousp/article/view/123777/119967>. Acesso em: Jul. 2017. ISSN: 2179-0892.

HEIDRICH, A. L. et al. Estrutura e dinâmica socioespacial das aglomerações urbanas em tempos de globalização. In HEIDRICH, A. L. et al. (Orgs.). Estruturas e dinâmicas socioespaciais urbanas no Rio Grande do Sul: transformações em tempos de globalização (1991-2010). Porto Alegre: Editora Letra 1, 2016, p. 7-21. 
IBGE - Instituto Brasileiro de Geografia e Estatística. 2010. Sistema IBGE de recuperação automática: banco de dados agregados. Rio de Janeiro: IBGE. Recuperado em 15 de Abril de 2017, de http:// www.sidra. ibge.gov.br.

JI, L.; ZHANG, L.; WYLIE, B. Analysis of Dynamic Thresholds for the Normalized Difference Water Index. Photogrammetric Engineering \& Remote Sensing [online]. Vol. 75. № 11. Nov. 2009, p. 1307-1317. Disponível em: < http://www.ibge.gov.br/home/geociencias/cartografia/default territ area.shtm >. Acesso em: Jul. 2017. ISSN: 0099-1112/09/7511-1307.

KÖPPEN, W. Climatología: con un estudio de los climas de la tierra. México, DF: Fondo de Cultura Económica, 1948.

LIN, J.; LIU, X.; LI, K.; LI, X. A maximum entropy method to extract urban land by combining MODIS reflectance, MODIS NDVI, and DMSP-OLS data. International Journal of Remote Sensing. V. 35 N 18 6708-6727, 2014.

MENGUE, V. P.; SCOTTÁ, F. C.; SILVA. T. S. S.; FARINA, F. Utilização do Modelo HAND para mapeamento das áreas mais suscetíveis à inundação no Rio Uruguai. Pesquisas em Geociências [online]. V. 43. № 1. Jan.-Abr. 2016, p. 41-53. Disponível em: http://www.ufrgs.br/igeo/pesquisas/4301/034301.pdf. Acesso em: Jul. 2017. ISSN: $1807-9806$.

MOMO, M. R.; PINHEIRO, A.; SEVERO, D. L.; CUARTAS, L. A.; NOBRE, A. D. Desempenho do modelo HAND no mapeamento de áreas suscetíveis à inundação usando dados de alta resolução espacial. RBRH [online]. Vol. 21. № 1. 2016, p.200-208. Disponível em: <http://www.scielo.br/scielo.php?script=sci_arttext\&pid=S231803312016000100200\&lng=en\&nrm=iso>. Acesso em: Jul. 2017. ISSN 2318-0331.

NOBRE, A. D.; CUARTAS, L. A.; HODNETT, M.; RENNÓ, C. D.; RODRIGUES, G.; SILVEIRA, A.; WATERLOO, M.; SALESKA, S. Height above the Nearest Drainage, a hydrologically relevant new terrain model. Journal Hydrology. v. 404, n. 1-2, p.13-29, 2011. doi:10.1016/j.jhydrol.2011.03.051

OLIVEIRA, G. G.; SALDANHA, D. L. ; GUASSELLI, L. A. Modelos para a espacialização e previsão de áreas inundáveis na zona urbana de São Sebastião do Caí, RS, Brasil. Pesquisas em Geociências [Online]. Vol. 38. № 2. Jun. 2012, p. 132-146. Disponível em: <http://seer.ufrgs.br/index.php/PesquisasemGeociencias/article/view/26379>. Acesso em: Jul. 2017. ISSN: 1807-9806.

OPOLOT, E. Application of remote sensing and geographical information systems in flood management: A Review. Research Journal of Applied Sciences, Engineering and Technology [online]. Vol. 6. № 10. Jul. 2013, p. 1884-1894. Disponível em: < http://maxwellsci.com/print/rjaset/v6-1884-1894.pdf >. Acesso em: Jul. 2017. ISSN: $2040-7467$.

PENG, J.; WANG, Y.; YE, M.; WU, J.; ZHANG, Y. Effects of Land-Use Categorization on Landscape Metrics: A Case Study in Urban Landscape of Shenzhen, China. International Journal of Remote Sensing [online]. Vol. 28 , № 21. Nov. 2007, p. 4877-4895. Disponível em: http://www.tandfonline.com/doi/full/10.1080/01431160601075590 >. Acesso em: Jul. 2017. ISSN: $1366-5901$.

RENNÓ, C.; NOBRE, A.D.; CUARTAS, L.A.; SOARES, J.V.; HODNETT, M.G.; TOMASELLA, J.; WATERLOO, M. HAND, a new terrain descriptor using SRTM-DEM: Mapping terra-firme rainforest environments in Amazonia. Remote Sensing of Environment [online]. Vol. 112, p.3469-3481, 2008. Disponível em: < http://www.sciencedirect.com/science/article/pii/S003442570800120X >. Acesso em: Jul. 2017. ISSN: 00344257.

SALDANHA, D. L. et al. Mapeamento e Avaliação das áreas inundáveis do Rio dos Sinos através da utilização de imagens TM-Landsat 5. Revista de Geografia da UNESP. Vol. 13. 1996, p. 127-144. ISSN: 0100-7912.

SANTOS, Milton. A Urbanização Brasileira. 5aed. São Paulo: Edusp, 2008. ISBN: 978-85-314-0860-1.

SCHEREN, R. S. Urbanização na planície de inundação do Rio Gravataí-RS. Dissertação de Mestrado em Geografia, UFRGS, 2014.

TORRES, H. G., ALVES, H. P. F.; OLIVEIRA, M. A. São Paulo peri-urban dynamics: some social causes and environmental consequences. Environment \& Urbanization Journal [online]. Vol. 19. № 1. Abr. 2007, p. 207223. Disponível em: < http://journals.sagepub.com/doi/pdf/10.1177/0956247807076784 >. Acesso em: Jul. 2017. ISSN: 1746-0301. 
TUCCI, C. E. M. Gestão da drenagem urbana. Brasília: CEPAL/IPEA, 2012. ISSN: 2179-5495.

VALERIANO, M. M.; ABDON, M. M. 2007. Aplicação de dados SRTM a estudos do Pantanal. Revista Brasileira de $\begin{array}{lcccccc}\text { Cartografia } \quad \text { [online]. } & \text { Vol. } & 59 . & \text { No1, p. } & 63-71 . & \text { Disponível em: } \\ \text { http://www.Isie.unb.br/rbc/index.php/rbc/article/view/297/286 } & \text { >. Acesso em: Jul. 2017. ISSN: 1808-0936. }\end{array}$ 